\title{
The importance of pathological quality control for rectal surgery
}

\author{
Alice C. Westwood, Nick P. West \\ Pathology \& Tumour Biology, Leeds Institute of Cancer and Pathology, University of Leeds, Leeds LS9 7TF, UK.
}

Correspondence to: Dr. Nick P. West, Pathology \& Tumour Biology, Level 4, Wellcome Trust Brenner building, St. James's University Hospital, Beckett Street, Leeds LS9 7TF, UK. E-mail: n.p.west@leeds.ac.uk

How to cite this article: Westwood AC, West NP. The importance of pathological quality control for rectal surgery. Mini-invasive Surg 2018;2:38. http://dx.doi.org/10.20517/2574-1225.2018.50

\author{
Received: 9 Jul 2018 First Decision: 11 Oct 2018 Revised: 26 Oct 2018 Accepted: 29 Oct 2018 Published: 31 Oct 2018 \\ Science Editor: Gordon N. Buchanan Copy Editor: Cai-Hong Wang Production Editor: Zhong-Yu Guo
}

\begin{abstract}
Pathologists are an integral member of the colorectal multidisciplinary team and are able to closely interact with surgeons, radiologists and oncologists to facilitate improvements in surgical quality and patient outcomes. Accurate, high quality pathology reports containing all vital prognostic information are essential to ensure the patient receives optimal treatment. These reports should also integrate feedback to all members of the multidisciplinary team on the accuracy of preoperative staging, response to preoperative treatment, and the quality of surgery. Pathologists have played a key role in improving outcomes in patients with rectal cancer by recognising the prognostic importance of an involved circumferential resection margin. In addition, pathologists have described an assessment of the surgical planes of dissection as a marker of surgical quality and thereby a means of quality control. This article will review the current best practice for the pathological assessment of anterior resections and abdominoperineal excisions for rectal cancer and ultimately look at how pathologists can influence quality control in rectal cancer surgery.
\end{abstract}

Keywords: Rectal cancer, pathological assessment, quality of surgery, mesorectal grading

\section{INTRODUCTION}

Pathologists play a key role in the modern multidisciplinary management of patients with rectal cancer. Pathological assessment of the resected specimen not only provides key prognostic information, e.g., primary staging of the tumour and identification of high risk features, but also allows evaluation of the quality of the surgery, accuracy of radiology, and an assessment of response to neoadjuvant therapy. Pathologists therefore have a unique opportunity, and responsibility, to provide feedback to all members of the multidisciplinary team (MDT), in particular surgeons, radiologists and oncologists, on the quality

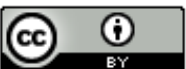

(C) The Author(s) 2018. Open Access This article is licensed under a Creative Commons Attribution 4.0 International License (https://creativecommons.org/licenses/by/4.0/), which permits unrestricted use, sharing, adaptation, distribution and reproduction in any medium or format, for any purpose, even commercially, as long as you give appropriate credit to the original author(s) and the source, provide a link to the Creative Commons license, and indicate if changes were made. 
of their services for audit, education and research purposes. This interaction is essential to optimise improving patient outcomes and ensure high quality care for patients with rectal cancer.

Total mesorectal excision (TME) has become the surgical treatment of choice in operable rectal cancer ${ }^{[1]}$, and high quality TME is vital in reducing the risk of local recurrence. If a patient with a low rectal cancer requires an abdominoperineal excision (APE), the mesorectum should be removed intact as for a TME but also careful thought should be given to the plane of dissection around the sphincters/levators. The quality of surgery can be determined by pathological assessment of the plane of dissection compared to the intended planes, with a focus on the mesorectal plane in all major resectional specimens ${ }^{[2]}$ and an additional assessment of the sphincter plane in $\mathrm{APE}^{[3]}$. In addition, involvement of the circumferential resection margin (CRM) can be used as a marker of the quality of surgery, although this is partly influenced by tumour extent ${ }^{[4]}$. Optimal surgery should aim for an intact specimen in the planned dissection plane with an uninvolved CRM.

Magnetic resonance imaging (MRI) is routinely used to stage rectal tumours preoperatively, to plan the optimal dissection plane and to re-assess tumours following neoadjuvant therapy. Pathologists provide feedback and quality control to radiologists on their accuracy of staging, prediction of CRM involvement, and response to neoadjuvant treatment. Oncologists can also benefit from feedback on response to neoadjuvant treatment, which gives important prognostic information and can be used to tailor further treatment.

Pathologists dissecting and analysing rectal cancer specimens must produce an accurate report not only containing all important staging and prognostic information, but also allowing the evaluation of the quality of other clinical services, notably radiology, surgery and oncology. For this reason, we advocate the use of a structured proforma for reporting, e.g., the Royal College of Pathologists dataset for colorectal cancer ${ }^{[5]}$.

This review will focus on how pathological assessment can be used to evaluate and optimise the quality of rectal cancer treatment as well as the evidence underpinning this.

\section{SURGICAL ANATOMY OF TMEIANTERIOR RESECTION SPECIMENS}

Above the anal sphincter complex, the muscularis propria of the rectum is surrounded by a variable layer of perirectal mesenteric fat known as the mesorectum, which is in direct continuity with the mesocolon. The mesorectum is of upmost importance in rectal cancer surgery as it contains all the structures, including blood vessels, nerves, lymphatic drainage, and lymph nodes, by which rectal cancers can potentially disseminate. A layer of visceral fascia completely surrounds the mesorectum below the peritoneal reflections, with this mesorectal fascia continuing posteriorly to the apex of the mesorectal triangle. Above the peritoneal reflections, the anterior and lateral mesorectum is covered by peritoneum [Figure 1]. The mesorectal fascia and peritoneum together create the external surface of a surgical "package", which should be removed intact with optimal TME surgery.

The volume of the mesorectum varies significantly between individuals and in different regions of the structure, with the greatest volume seen posteriorly and a thinner layer anteriorly ${ }^{[6]}$. It is therefore unsurprising that involvement of the CRM and intra-operative perforations are more commonly seen at the anterior aspect of the specimen ${ }^{[6,7]}$. The greatest volume of mesorectum is found in the mid rectum, distal to which the structure gradually narrows to a point of maximum wasting at the level of puborectalis, approximately $4 \mathrm{~cm}$ above the anal verge ${ }^{[8]}$.

During TME surgery, the aim is to perform precise dissection within the mesorectal fascial plane to create an intact surgical "package" containing the primary tumour and surrounding mesorectum ${ }^{[1]}$. The nonperitonealised surface of the specimen forms the surgically created CRM, although this margin is only 


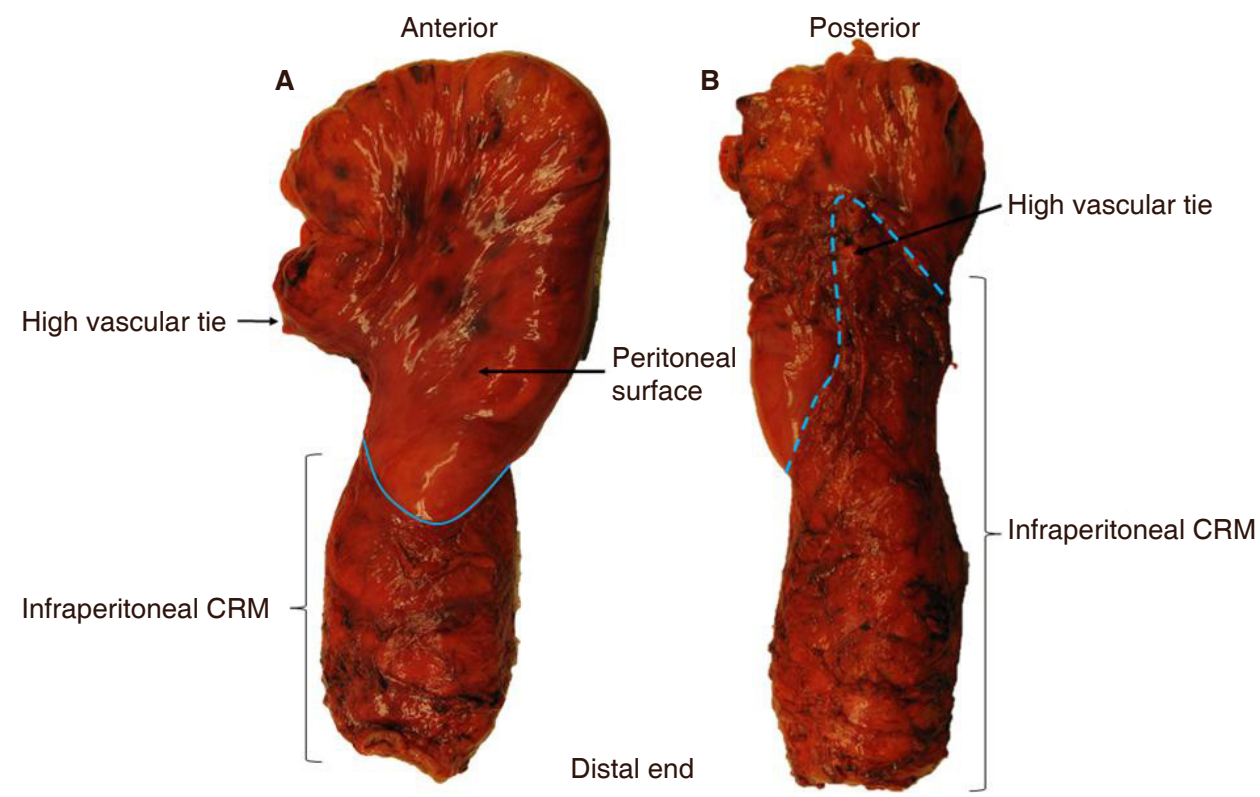

Figure 1. Anterior resection specimen for rectal cancer demonstrating the peritoneal reflection (marked in blue solid line) at the anterior aspect (A) and the mesorectal apex (marked in blue dotted line) at the posterior aspect (B). CRM: circumferential resection margin

truly circumferential below the level of the anterior peritoneal reflection. The CRM should be covered by mesorectal fascia if surgery has been carried out in the optimal mesorectal plane ${ }^{[1]}$.

Involvement of the CRM by tumour, defined as tumour $1 \mathrm{~mm}$ or less from the margin, is strongly associated with local recurrence and is an adverse prognostic feature ${ }^{[4,9]}$. This involvement can occur through direct extension of the main tumour; by tumour in nerves, blood vessels, lymphatic channels or lymph nodes; or discontinuous tumour deposits ${ }^{[5]}$. Advances in MRI mean that radiologists can make excellent predictions for CRM involvement and play a vital role in selecting patients who may benefit from preoperative therapy ${ }^{[10]}$.

There are two main causes of the primary tumour involving the CRM. Either the tumour is advanced and involving the mesorectal fascia, or the tumour is clear of the fascia but the surgeon has failed to stay in the correct dissection plane. Advanced tumours extending to within $1 \mathrm{~mm}$ of the mesorectal fascia should be identified in advance by MRI and may benefit from more extensive surgery or preoperative treatment to shrink the tumour to a surgically resectable state. If the CRM is involved by primary tumour with the specimen in the mesorectal plane, either the involved CRM should have been expected or the radiologist has failed to identify the advanced nature of the disease.

The introduction of TME and surgical training initiatives have led to a significant reduction in the rate of local recurrence and improved survival in both large-scale population series and clinical trials ${ }^{[11-13]}$. A major contributing factor to this improvement is thought to be the reduction in CRM involvement and suboptimal planes of surgery associated with $\mathrm{TME}^{[4]}$.

\section{SURGICAL ANATOMY OF APE SPECIMENS}

APE of the rectum and anus is frequently utilised as the surgical treatment of choice in patients with advanced low rectal tumours (within $6 \mathrm{~cm}$ of the anal verge), although the operation may be used for higher tumours if poor function is predicted. The "conventional" APE involves an abdominal and a perineal phase; the abdominal phase is essentially a TME, and this is followed by the perineal phase, traditionally with the patient in the lithotomy position, that involves dissection outside the anal sphincters to meet the TME plane. 
Approximately $25 \%$ of patients with rectal cancer undergo APE surgery, although there is considerable variation in APE rates between hospitals ${ }^{[14,15]}$. There have been concerns raised that APE surgery is overused in some centres and it has been proposed that the rate of APE surgery may be used as a surrogate marker for surgical quality ${ }^{[16,17]}$. The outcome after APE surgery for low rectal cancer in several studies is poorer in terms of patient outcome when compared to anterior resections for higher rectal tumours ${ }^{[6,18]}$. As previously described, the mesorectum narrows to a waist at the level of puborectalis and commencement of the sphincters, therefore unlike mid or high rectal tumours, there is less protective tissue between the tumour and the CRM in low rectal tumours when following the "conventional" TME plane. In addition, visualisation in a "conventional" APE may be poor in the lithotomy position during perineal dissection and may lead to surgeons deviating into the wrong tissue plane. These factors are likely to account for the increased CRM involvement rate in APE surgery ${ }^{[6,7]}$ and increased risk of intraoperative perforations ${ }^{[1,20]}$. In cases of advanced anterior tumours, an en bloc prostatectomy or resection of the posterior vaginal wall may be carried out due to the negligible perirectal tissue present anteriorly, in order to increase the chances of an Ro resection ${ }^{[6]}$.

Development of more radical techniques for advanced tumours, e.g., extralevator APE has led to improved clinical outcomes in some studies through a reduction in CRM involvement and perforations compared to "conventional" APE surgery ${ }^{[7,21,22]}$. Extralevator APE involves the removal of the levator ani with the mesorectum and anal sphincters, creating a more cylindrically shaped specimen and thereby providing critical extra tissue around a low rectal tumour ${ }^{[22]}$. Surgical variations in this technique, including use of the prone jack-knife position, mean that visualisation of the perineal dissection is also improved, helping to reduce the risk of straying into the wrong tissue plane ${ }^{[22]}$. A multicentre European study comparing a large series of extralevator APE to "conventional" APE found that extralevator APE removed significantly more tissue around low rectal cancers with a reduction in CRM involvement (50\% to $20 \%, P<0.001)$ and reduction in intraoperative perforations ( $28 \%$ to $8 \%, P<0.001)^{[23]}$. Similarly, a 2011 systematic review found a reduction when comparing extralevator APE to conventional APE in CRM involvement $(9.6 \%$ vs. $15.4 \%, P=0.022)$, bowel perforation $(4.1 \%$ vs. $10.4 \%, P=0.004)$, and local recurrence rate $(6.6 \% v s .11 .9 \%, P<0.001)^{[24]}$.

\section{THE ROLE OF PHOTOGRAPHY IN SPECIMEN QUALITY CONTROL}

A key component in facilitating feedback on the quality of surgical specimens is keeping a permanent record of each specimen using digital photography. Digital images should be taken of the anterior and posterior aspect of the whole intact specimen, preferably prior to inking, opening and fixation, alongside a metric scale for calibration. Any significant defects in the mesorectal fascia, sphincters or perforations warrant a close-up image. Similarly, digital images should be routinely taken of the serial cross-sectional slices taken at 3-5 $\mathrm{mm}$ intervals through the tumour to confirm the plane of surgery and demonstrate the relationship of the tumour to the CRM. In APE, additional close-up images should be taken of the front and back of the anal canal/sphincter/levator area to record the plane of surgery in this area. Lateral images may also be helpful. These images should be stored in a departmental archive and should be actively used in MDT meetings to feed back to surgical colleagues and compare to the radiological appearances. In addition they can be used for education, research and audit purposes.

\section{PATHOLOGICAL ASSESSMENT OF ANTERIOR RESECTION SPECIMENS}

The anatomy of the specimen depends on several factors including the positioning of the tumour, the quality of surgical dissection, whether a partial or total mesorectal excision has been performed, whether additional structures have been removed and the individual variation in height of the peritoneal reflections. The first step is to grade the quality of the mesorectum. The recommended three-point grading system for assessment of mesorectal dissection can be seen in Table $1^{[25]}$ and macroscopic images demonstrating these planes of dissection can be found in the Royal College of Pathologists dataset for colorectal cancer ${ }^{[5]}$. Examples of mesorectal and intramesorectal plane surgery can be seen in Figure 2. 
Table 1. Three-point grading system for the assessment of the plane of mesorectal dissection in total mesorectal excision/ anterior resection specimens for rectal cancer

\begin{tabular}{|c|c|c|}
\hline Grade of excision & Quality of surgery & Description \\
\hline Mesorectal & Good surgery & $\begin{array}{l}\text { Intact smooth mesorectal surface with only minor irregularities. Any defects must be no } \\
\text { deeper than } 5 \mathrm{~mm} \text {. No coning of the specimen distally. Smooth CRM on slicing }\end{array}$ \\
\hline Intramesorectal & Moderate surgery & $\begin{array}{l}\text { Moderate bulk to mesorectum but irregularity of the mesorectal surface. Moderate distal } \\
\text { coning. Muscularis propria not visible with the exception of levator insertion. Moderate } \\
\text { irregularity of CRM on slicing }\end{array}$ \\
\hline Muscularis propria & Poor surgery & $\begin{array}{l}\text { Little bulk to mesorectum with defects down onto the muscularis propria and/or very } \\
\text { irregular CRM. It includes perforations through the CRM }\end{array}$ \\
\hline
\end{tabular}

CRM: circumferential resection margin

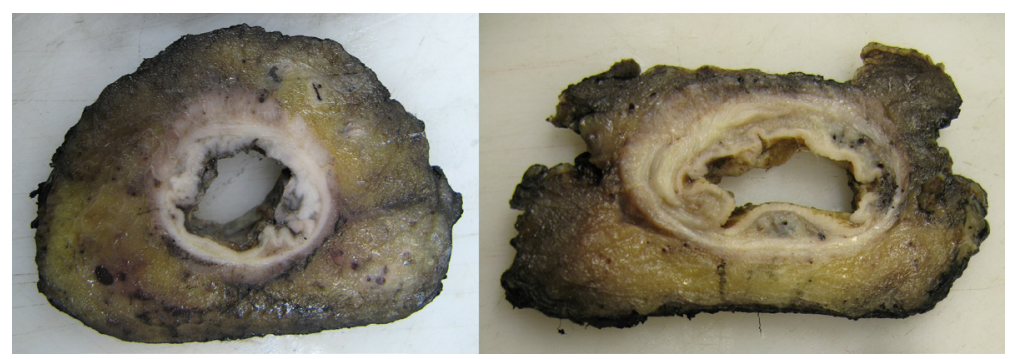

Figure 2. Cross sectional slices showing a mesorectal plane specimen with smooth circumferential resection margin (CRM) (left) and intramesorectal plane specimen with irregularity to the CRM and obvious defects, but no evidence of defects extending to the muscle tube (right)

Grading of the mesorectal plane of excision is a key marker for surgical quality and plays a vital role in providing continual feedback to the MDT team for educational and audit purposes. Feeding back the planes of mesorectal surgery in the MRC CR07 trial led to a gradual improvement in specimen quality over the duration of the trial ${ }^{[2]}$.

Prior to dissecting the specimen, the external surface should be carefully examined by a histopathologist to ensure all key prognostic features are identified and described. We recommend the description and dissection method developed in Leeds and adopted by the Royal College of Pathologists for use in colorectal cancer reporting to ensure consistent and thorough assessment ${ }^{[5,27]}$. It is essential that the specimen is received intact, and preferably fresh, to allow accurate assessment of both the mesorectal plane and the CRM, as well as taking the whole specimen photographs. The mesorectal fascia may be easier to identify and assess in fresh tissue as it will appear as a shiny smooth layer, whereas following formalin fixation the fascia can become distorted and appear dull and opaque.

Any disruptions in the mesorectal fascia should be described in terms of their depth and extent, and the presence of surgical perforation, a communication between the surface of the specimen and the lumen of the bowel, should also be documented in the pathology report [Figure 3]. Tumour perforations above the peritoneal reflections are associated with an increased risk of intraperitoneal recurrence and have a poor $\operatorname{prognosis}^{[28]}$; these are classified as pT4a using TNM8 staging ${ }^{[22]}$. Perforations through the CRM commonly occur in addition to perforations through the peritoneum, especially in APE specimens, and usually involve the anterior aspect, where the mesorectum is at its thinnest ${ }^{[19]}$. Although technically not classified as pT4a under TNM rules, these are also associated with a high risk of local recurrence ${ }^{[20]}$ and reduced survival ${ }^{[30]}$.

\section{PATHOLOGICAL ASSESSMENT OF APE SPECIMENS}

APE specimens should be received intact, ideally fresh and should be assessed by pathologists in a very similar way to that for anterior resection specimens as described above. Specifically, the mesorectal plane of excision and presence of intraoperative perforations should be evaluated and specimen photographs should 


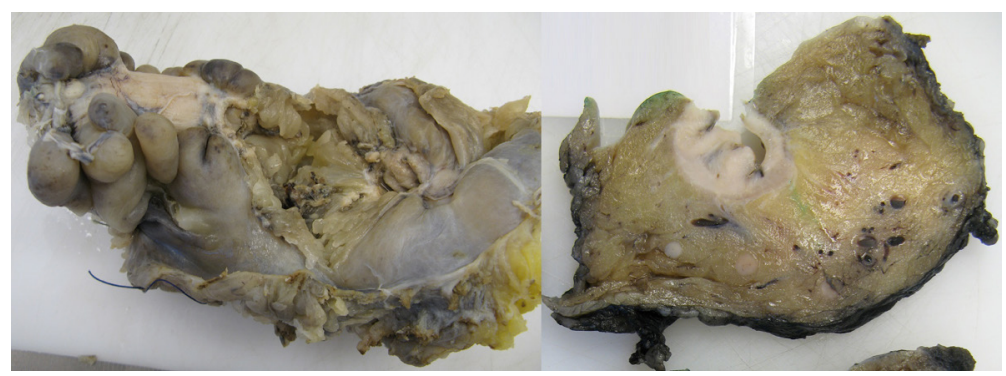

Figure 3. Anterior resection specimen showing a large anterior perforation with a defect into the lumen of the bowel (left), which is confirmed on cross sectional slicing where part of the anterior rectal wall is missing (right)
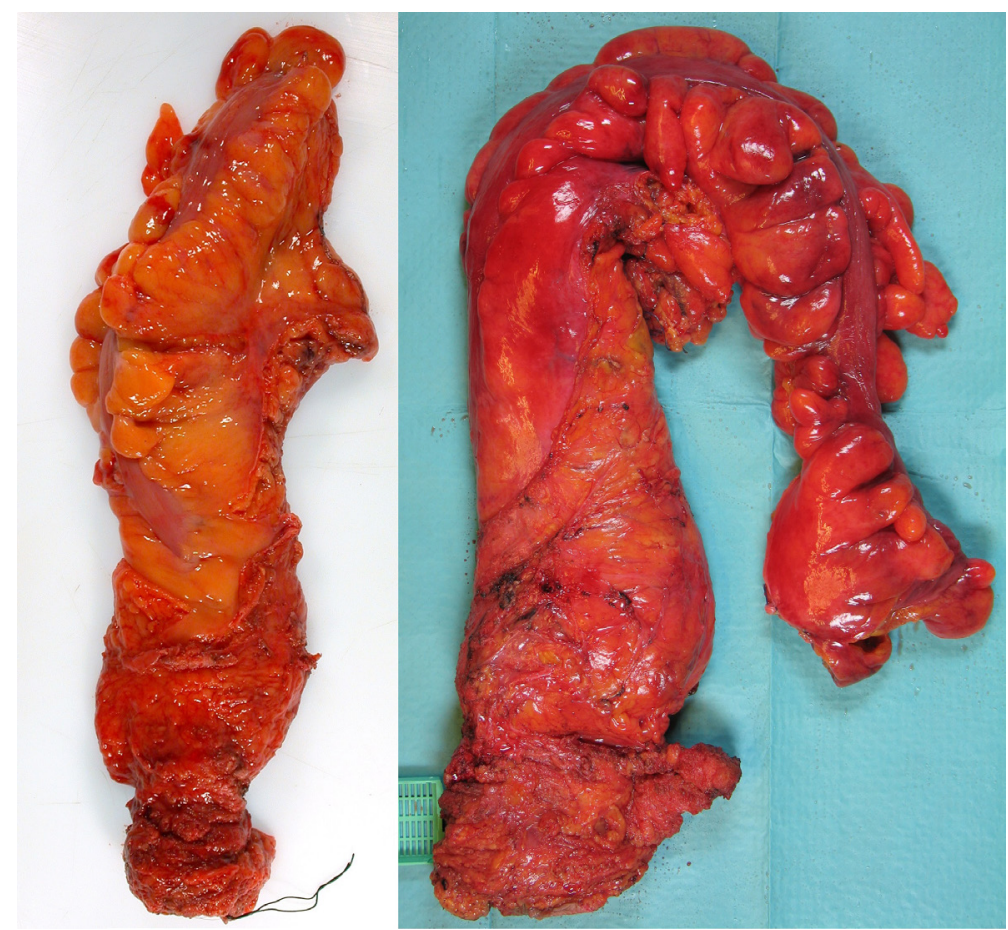

Figure 4. Two abdominoperineal specimens, the first resected in the sphincteric plane with an obvious area of waisting towards the base of the mesorectum/top of the sphincters (left) and the second resected in the extra-levator plane with no visible waisting (right)

be taken. An additional assessment of the surgical plane of dissection around the levator/sphincter area is an important indicator of APE quality and needs to be assessed carefully by the pathologist; macroscopic images demonstrating the three surgical planes of dissection can be found in the Royal College of Pathologists dataset for colorectal cancer ${ }^{[5]}$. A study by Martijnse et al.$^{[31]}$ is an example of how an increased focus on the quality of perineal dissection in APE surgery can lead to improved quality of surgery and a significant reduction in the number of involved resection margins [Figure 4]. The recommended threepoint grading system can be seen in Table $2^{[3]}$.

\section{PATHOLOGICAL ASSESSMENT OF THE CRM}

Involvement of the CRM is a key prognostic marker in rectal cancer and therefore care needs to be taken to ensure accurate histopathological assessment. The importance of an involved CRM increases after preoperative treatment as it is associated with increased risk of local failure, local recurrence and poor survival ${ }^{[9,18]}$.

Following macroscopic assessment of the mesorectal plane (and sphincter planes in APE), whole specimen photography and after a period of formalin fixation (at least 48 hours to facilitate thin cross sectional 
Table 2. Three-point grading system for the assessment of the plane of anal canal/sphincter dissection in abdominoperineal excision specimens for low-rectal cancer

\begin{tabular}{ll}
\hline Grade & \multicolumn{1}{c}{ Description } \\
\hline Extra-levator plane & $\begin{array}{l}\text { The specimen has a cylindrical shape due to the presence of levator ani removed en bloc with the mesorectum and } \\
\text { sphincters. Any defects must be no deeper than } 5 \mathrm{~mm} \text {. No waisting of the specimen. Smooth CRM on slicing } \\
\text { The specimen is waisted and the CRM in this region is formed by the surface of the sphincter muscles which have } \\
\text { been removed intact } \\
\text { Thincteric plane }\end{array}$ \\
$\begin{array}{l}\text { Intrasphincteric plane } \\
\text { The specimen is waisted and includes deviations into the sphincter muscles, submucosa and complete perforations }\end{array}$
\end{tabular}

CRM: circumferential resection margin

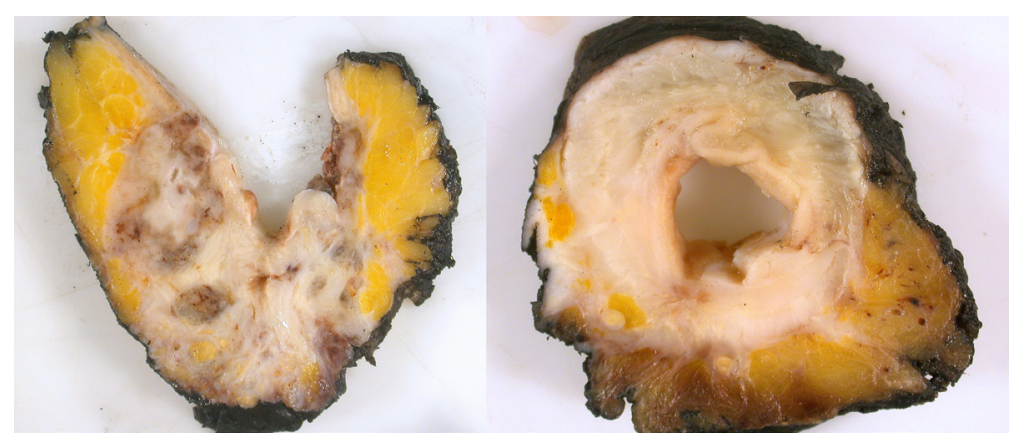

Figure 5. Cross sectional slices from two specimens showing involvement of the circumferential resection margin (CRM) by primary tumour. The first has macroscopically visible tumour extending to the margin and was correctly identified as CRM involved on MRI (left); the second has extensive fibrosis following pre-operative chemoradiotherapy and the post treatment MRI predicted a clear margin, but small microscopic islands of residual viable tumour were present at the CRM (right)

slices), the CRM of the specimen should be inked, e.g., with India ink to allow histological identification of the margin and accurate measurement. It is important that the peritoneal surface is not inked as involvement of the peritoneum is a risk factor for peritoneal recurrence rather than the local recurrence seen following CRM involvement.

The specimen should then be sliced transversely at 3-5 $\mathrm{mm}$ intervals and the slices laid out sequentially to visualise the relationship between the tumour and the CRM. A minimum of five tumour blocks should be processed for histological examination and at least one should include the closest tumour to the inked $\mathrm{CRM}^{[5]}$. Tumour can involve the CRM through primary extension, discontinuous spread/tumour deposits, lymph node metastases (with and without extracapsular spread) and along nerves, veins and lymphatics [Figure 5]. Any lymph nodes or suspicious vascular structures close to the CRM should therefore be embedded with the inked margin intact. It is mandatory that the pathology report includes a comment regarding tumour involvement of the CRM, as if appropriate the patient may be offered adjuvant therapy to reduce the subsequent risk of local recurrence ${ }^{[5,32]}$. The nearest distance of the tumour to the CRM should also be recorded and if involved the mechanism and extent of involvement may be helpful. It should be noted that the relative importance of lymph node metastases at the CRM is relatively underreported, however, limited evidence suggests that this may have less impact than other mechanisms of involvement ${ }^{[4]}$. Biologically one would expect that tumour in a lymph node with an intact lymph node capsule and intact mesorectal fascia is likely to have a lower risk of local recurrence when compared to extracapsular lymph node spread with mesorectal defects.

The status of the CRM and mechanisms of involvement should be specifically fed back to the radiologists at the MDT meeting to enable them to audit their preoperative predictions for CRM involvement. Radiological assessment following neoadjuvant therapy is of increasing importance; MRI prediction of involvement of the CRM following preoperative treatment is associated with a greater risk of local recurrence $^{[33]}$. Feedback from the pathologist as to whether any fibrosis extends towards the CRM is very helpful to enable correlation with MRI findings. In cases where there is a discrepancy between the 
radiological prediction and the final pathology, effort should be made by the pathologist to indicate why this is the case. One important factor may be correlation with the plane of surgery, i.e., an involved margin being caused by failure to resect in the planned dissection plane. Another common cause of discrepancy is the identification of CRM involvement through microscopic nodal deposits and small vessel invasion that could not be visualised radiologically.

Feedback on the degree of response to neoadjuvant treatment is also very helpful for the oncologists in terms of regression away from the CRM and general tumour regression grading in order to understand the sensitivity of individual tumours to specific treatments and to plan subsequent treatment. The four point tumour regression grading system from TNM8 should be used in all pathology reports; this can be found in the latest Royal College of Pathologists dataset for colorectal cancer ${ }^{[5,29]}$.

\section{THE ROLE OF MDT EDUCATION IN IMPROVING THE QUALITY OF TREATMENT FOR RECTAL CANCER}

The MDT provides a patient-centred forum and an opportunity to optimise the treatment plan, improve quality of care for patients with cancer, and is likely linked to improved rates of curative resection ${ }^{[34]}$. Education of the MDT gives a unique opportunity to optimise surgical practice, improve decision making for preoperative treatment, and advance the overall quality of care for patients ${ }^{[35]}$. Education programmes directed primarily at surgeons have been shown to improve the oncological quality of surgical specimens and patient outcomes in Netherlands, Norway and Sweden ${ }^{[13]}$. The National Pelican MDT TME Development Programme was an educational programme aimed at the whole CRC MDT and was delivered through the Pelican Cancer Foundation in England ${ }^{[36]}$. Although there is limited evidence for the direct effect of the programme, outcomes for rectal cancer patients in the UK were significantly improved over this time period and a further government funded National MDT educational programme focusing on low rectal cancer called the Low Rectal Cancer Development Programme (LOREC) was launched a few years later ${ }^{[37]}$. The aim of LOREC was to improve the poor outcomes associated with low rectal cancer by focusing on preoperative imaging, selective neoadjuvant therapy, optimal surgical treatment, specialist nursing, and detailed histopathological assessment. LOREC ran workshops for all colorectal MDT members and take-up across England was excellent with approximately $90 \%$ of MDTs attending and a total 1019 participants ${ }^{[37]}$. These received excellent feedback and $96 \%$ of surgeons attending said it would alter their future practice ${ }^{[37,38]}$; local audit has also shown a change in surgical practice associated with good outcomes following the workshops ${ }^{[39]}$. LOREC has shown the potential positive impact that education on MDTs can have. A further programme focusing on early colorectal cancers, the Significant Polyp \& Early Colorectal Cancer, has recently finished and there is an ongoing programme, Improving Management for Patients with Advanced Colorectal Tumour, with a focus on advanced and metastatic cancers ${ }^{[40]}$.

\section{CONCLUSION}

Outcomes for patients with rectal cancer have markedly improved over the last two decades; these improvements have resulted from a number of interventions including the description and widespread introduction of TME surgery $y^{[1,41]}$, the use of MRI for preoperative staging ${ }^{[42,43]}$, and the use of neoadjuvant treatment ${ }^{[4,45]}$. Histopathologists who dissect and report rectal cancer specimens have played an essential role in improving patient outcomes by recognising the importance of the $\mathrm{CRM}^{[9]}$, as well as describing the assessment of surgical planes of dissection as a means of quality control ${ }^{[26]}$. More recent focus has been on the poor outcomes associated with traditional APE surgery for low rectal cancer and pathologists have played a vital role in this, by identifying evidence to support changes in practice for surgeons, radiologists, oncologists and pathologists. Many of these improvements have been supported by national MDT education/development programmes leading to a rapid uptake in optimal practice. 
In summary, pathologists are able to assess the quality of surgery of anterior resections by assessing the plane of mesorectal excision, involvement of the CRM and presence of intraoperative perforations. In APE specimens, the same quality markers are used with the addition of an assessment of the plane of sphincter/ levator dissection as a surrogate marker for surgical quality in the critical area commonly associated with CRM involvement/perforations. Feedback on the planes of surgery, as well as other important prognostic information, is essential to the MDT and can benefit not only surgeons, but oncologists and radiologists. Pathologists must provide detailed, accurate reports encompassing all important prognostic markers as well as an evaluation of surgical quality. Consistent feedback to the colorectal MDT is essential to further improve outcomes for patients with rectal cancer.

\section{DECLARATIONS}

\section{Author's contributions}

Equally involved with the literature research and manuscript writing: Westwood AC, West NP

\section{Availability of data and materials}

Not applicable.

\section{Financial support and sponsorship}

Westwood AC is supported by Cancer Research UK and the Pathological Society of Great Britain and Ireland pre-doctoral research Bursary. West NP is supported by Yorkshire Cancer Research.

\section{Conflicts of interest}

The two authors declared that there are no conflicts of interest.

\section{Ethical approval and consent to participate}

Not applicable.

\section{Consent for publication}

Not applicable.

\section{Copyright}

(c) The Author(s) 2018.

\section{REFERENCES}

1. Heald R, Ryall R. Recurrence and survival after total mesorectal excision for rectal cancer. Lancet 1986;327:1479-82.

2. Bosch SL, Nagtegaal ID. The importance of the pathologist's role in assessment of the quality of the mesorectum. Curr Colorectal Cancer Rep 2012;8:90-8.

3. Nagtegaal ID, van de Velde CJ, Marijnen CA, van Krieken JH, Quirke P. Low rectal cancer: a call for a change of approach in abdominoperineal resection. J Clin Oncol 2005;23:9257-64.

4. Birbeck KF, Macklin CP, Tiffin NJ, Parsons W, Dixon MF, et al. Rates of circumferential resection margin involvement vary between surgeons and predict outcomes in rectal cancer surgery. Ann Surg 2002;235:449.

5. Loughrey M, Quirke P, Shepherd N. Standards and datasets for reporting cancers: dataset for colorectal cancer. London: The Royal College of Pathologists; 2017.

6. Marr R, Birbeck K, Garvican J, Macklin CP, Tiffin NJ, et al. The modern abdominoperineal excision: the next challenge after total mesorectal excision. Ann Surg 2005;242:74.

7. West NP, Finan PJ, Anderin C, Lindholm J, Holm T, et al. Evidence of the oncologic superiority of cylindrical abdominoperineal excision for low rectal cancer. J Clin Oncol 2008;26:3517-22.

8. Salerno G, Chandler I, Wotherspoon A, Thomas K, Moran B, et al. Sites of surgical waisting in the abdominoperineal specimen. Br J Surg 2008;95:1147-54.

9. Quirke P, Dixon M, Durdey P, Williams N. Local recurrence of rectal adenocarcinoma due to inadequate surgical resection: histopathological study of lateral tumour spread and surgical excision. Lancet 1986;328:996-9.

10. Mercury Study Group. Diagnostic accuracy of preoperative magnetic resonance imaging in predicting curative resection of rectal cancer: prospective observational study. BMJ 2006;333:779. 
11. Kapiteijn E, Putter H, Van de Velde C. Impact of the introduction and training of total mesorectal excision on recurrence and survival in rectal cancer in The Netherlands. Br J Surg 2002;89:1142-9.

12. Martling AL, Holm T, Rutqvist L, Moran B, Heald R, et al. Effect of a surgical training programme on outcome of rectal cancer in the County of Stockholm. Lancet 2000;356:93-6.

13. Wibe A, Møller B, Norstein J, Carlsen E, Wiig JN, et al. A national strategic change in treatment policy for rectal cancer-implementation of total mesorectal excision as routine treatment in Norway. A national audit. Dis Colon Rectum 2002;45:857-66.

14. Morris E, Birch R, West N, Finan P, Forman D, et al. Low abdominoperineal excision rates are associated with high-workload surgeons and lower tumour height. Is further specialization needed? Colorectal Dis 2011;13:755-61.

15. Tilney HS, Heriot AG, Purkayastha S, Antoniou A, Aylin P, et al. A national perspective on the decline of abdominoperineal resection for rectal cancer. Ann Surg 2008;247:77-84.

16. Morris E, Quirke P, Thomas JD, Fairley L, Cottier B, et al. Unacceptable variation in abdominoperineal excision rates for rectal cancer: time to intervene? Gut 2008;57:1690-7.

17. Tilney H, Tekkis P, Heriot A. Report of the national bowel cancer audit project: assessing quality. London: Association of Coloproctology of Great Britain \& Ireland; 2006.

18. Nagtegaal ID, Quirke P. What is the role for the circumferential margin in the modern treatment of rectal cancer? J Clin Oncol 2008;26:303-12.

19. How P, Shihab O, Tekkis P, Brown G, Quirke P, et al. A systematic review of cancer related patient outcomes after anterior resection and abdominoperineal excision for rectal cancer in the total mesorectal excision era. Surg Oncol 2011;20:e149-55.

20. Zhang XM, Dai JL, Ma SH, Liang JW, Wang Z, et al. Intra-operative perforation: a risk factor for prognosis of low rectal cancer after abdominoperineal resection. Med Oncol 2014;31:964.

21. De Nardi P, Summo V, Vignali A, Capretti G. Standard versus extralevator abdominoperineal low rectal cancer excision outcomes: a systematic review and meta-analysis. Ann Surg Oncol 2015;22:2997-3006.

22. Holm T, Ljung A, Häggmark T, Jurell G, Lagergren J. Extended abdominoperineal resection with gluteus maximus flap reconstruction of the pelvic floor for rectal cancer. Br J Surg 2007;94:232-8.

23. West N, Anderin C, Smith K, Holm T, Quirke P. Multicentre experience with extralevator abdominoperineal excision for low rectal cancer. Br J Surg 2010;97:588-99.

24. Stelzner S, Koehler C, Stelzer J, Sims A, Witzigmann H. Extended abdominoperineal excision vs. standard abdominoperineal excision in rectal cancer--a systematic overview. Int J Colorectal Dis 2011;26:1227.

25. Quirke P, Thorpe H, Dewberry S. Prospective assessment of the quality of surgery in the MRC CLASICC trial evidence for variation in the plane of surgery in colon cancer, local recurrence and survival. Birmingham, United Kingdom: National Cancer Research Institute conference; 2008.

26. Quirke P, Steele R, Monson J, Grieve R, Khanna S, et al. Effect of the plane of surgery achieved on local recurrence in patients with operable rectal cancer: a prospective study using data from the MRC CR07 and NCIC-CTG CO16 randomised clinical trial. Lancet 2009;373:821-8.

27. Quirke P, Dixon M. The prediction of local recurrence in rectal adenocarcinoma by histopathological examination. Int J Colorectal Dis 1988:3:127-31.

28. Eriksen M, Wibe A, Syse A, Haffner J, Wiig J. Inadvertent perforation during rectal cancer resection in Norway. Br J Surg 2004;91:210-6.

29. Union for International Cancer Control. TNM Classification of Malignant Tumours. Oxford, UK: Wiley-Blackwell; 2017.

30. Bülow S, Christensen IJ, Iversen LH, Harling H; Danish Colorectal Cancer Group. Intra-operative perforation is an important predictor of local recurrence and impaired survival after abdominoperineal resection for rectal cancer. Colorectal Dis 2011;13:1256-64.

31. Martijnse IS, Dudink RL, West NP, Wasowicz D, Nieuwenhuijzen GA, et al. Focus on extralevator perineal dissection in supine position for low rectal cancer has led to better quality of surgery and oncologic outcome. Ann Surg Oncol 2012;19:786-93.

32. National Institute for Health and Care Excellence. Colorectal cancer: diagnosis and management [CG131]. London; 2014.

33. Patel UB, Taylor F, Blomqvist L, George C, Evans H, et al. Magnetic resonance imaging-detected tumor response for locally advanced rectal cancer predicts survival outcomes: MERCURY experience. J Clin Oncol 2011;29:3753-60.

34. Burton S, Brown G, Daniels I, Norman A, Mason B, et al. MRI directed multidisciplinary team preoperative treatment strategy: the way to eliminate positive circumferential margins? Br J Cancer 2006;94:351.

35. Jessop J, Beagley C, Heald R. The Pelican Cancer Foundation and The English National MDT-TME Development Programme. Colorectal Dis 2006;8:1-2.

36. Taylor C, Sippitt JM, Collins G, McManus C, Richardson A, et al. A pre-post test evaluation of the impact of the PELICAN MDT-TME Development Programme on the working lives of colorectal cancer team members. BMC health Serv Res 2010;10:187.

37. Moran B, Holm T, Brannagan G, Chave H, Quirke P, et al. The English national low rectal cancer development programme: key messages and future perspectives. Colorectal Dis 2014;16:173-8.

38. Foster J, Gash K, Carter F, West N, Acheson A, et al. Development and evaluation of a cadaveric training curriculum for low rectal cancer surgery in the English LOREC National Development Programme. Colorectal Dis 2014;16.

39. Blong J, Chhabra A, James K, Arumagam P, Feldman M. PWE-403 Impact of the lorec programme on low rectal cancer surgery in a UK hospital. Gut 2015;64:A387-8.

40. Moran B, Dattani M. "SPECC and SPECULATION": Is a significant polyp benign or an early colorectal cancer? How do we know and what do we do? Colorectal Dis 2016;18:745-8.

41. Heald R, Husband E, Ryall R. The mesorectum in rectal cancer surgery--the clue to pelvic recurrence? Br J Surg 1982;69:613-6.

42. Beets-Tan R, Beets G, Vliegen R, Kessels A, Van Boven H, et al. Accuracy of magnetic resonance imaging in prediction of tumour-free resection margin in rectal cancer surgery. Lancet 2001;357:497-504. 
43. Brown G, Richards CJ, Newcombe RG, Dallimore NS, Radcliffe AG, et al. Rectal carcinoma: thin-section MR imaging for staging in 28 patients. Radiology 1999;211:215-22.

44. Stockholm Rectal Cancer Study Group. Preoperative short-term radiation therapy in operable rectal carcinoma: a prospective randomized trial. Cancer 1990;66:49-55.

45. Sauer R, Fietkau R, Wittekind C, Rödel C, Martus P, et al. Adjuvant vs. neoadjuvant radiochemotherapy for locally advanced rectal cancer: the German trial CAO/ARO/AIO-94. Colorectal Dis 2003;5:406-15. 